\title{
Gold(I)-Catalyzed Synthesis of Highly Substituted 1,4-Dicarbonyl Derivatives via Sulfonium [3,3]-Sigmatropic Rearrangement
}

\author{
Weiping Zhou and Arnaud Voituriez*
}

Université Paris-Saclay, CNRS, Institut de Chimie des Substances Naturelles, UPR 2301, 91198, Gif-sur-Yvette, France.

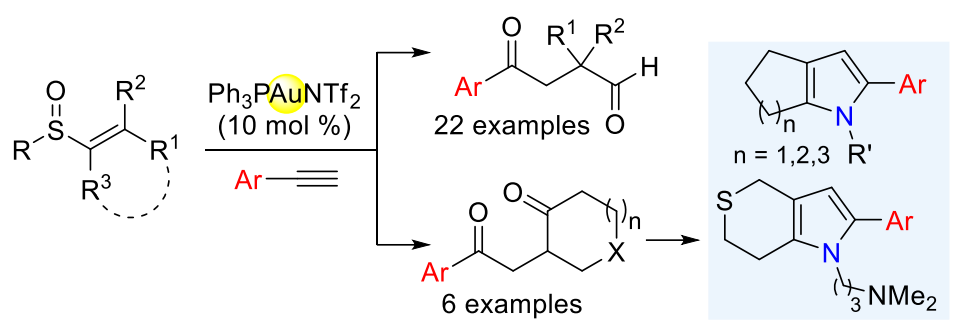

\begin{abstract}
An efficient and straightforward gold-catalyzed protocol for the synthesis of 2-substituted-4-oxo-4-arylbutanal derivatives has been developed from commercially available or easily accessible alkynes and vinylsulfoxide substrates. Extension of the methodology to the use of 1-cycloalkenyl sulfoxides allowed the facile synthesis of five, six and seven-membered ring cycloalkyl1 -one backbone. Subsequently, the tetrahydrocycloalkyl[ $b]$ pyrrole derivatives, found in many active pharmaceutical ingredients (APIs), were isolated in good yields. Mechanistic investigation highlighted in this process a [3,3]-sigmatropic rearrangement of a sulfonium intermediate.
\end{abstract}

1,4-Dicarbonyl derivatives are widely present as structural motifs in natural products and bioactive molecules. ${ }^{1}$ These compounds are also useful building blocks and starting materials for different reactions such as the Paal-Knorr synthesis, to easily prepare heterocycles (furan, thiophene, pyrrole,...) from the same key intermediate. ${ }^{2}$ Many different strategies have been described for the synthesis of these valuable scaffolds, such as oxidative couplings ${ }^{3}$ or umpolung processes, $^{4 \mathrm{a}-\mathrm{e}}$ including enolate $\mathrm{f}^{4 \mathrm{f}-\mathrm{i}}$ and radical-based transformations, ${ }^{4 j-o}$ and others. ${ }^{5}$ However, each of these approaches are necessarily limited to specific substrates, and several methods failed to construct quaternary centers or to use easy-to-handle reagents. In the framework of this study, we proposed to develop a gold(I)-catalyzed sulfonium [3,3]sigmatropic rearrangement, for the synthesis of highly functionalized 1,4-dicarbonyls.

Indeed, in the recent years, cascade reactions including [3,3]sigmatropic rearrangement of sulfur-containing substrates has emerged as powerful strategies for the synthesis of molecules of interest. ${ }^{6}$ In 2007, Toste and Zhang independently described the intramolecular gold-catalyzed alkynyl arylsulfoxide transformation, to furnish the seven-membered thiepinone ring (Scheme 1a). ${ }^{7 \mathrm{a}-\mathrm{b}}$ Initially, it was proposed that the reaction intermediate was an $\alpha$-oxo gold carbene, but it was demonstrated later that the reaction most certainly proceeded through a [3,3]-sigmatropic rearrangement, via intermediate (I). ${ }^{7 \mathrm{c}}$ The intermolecular version of this reaction was then exemplified with aryl sulfoxide substrates (Scheme 1b). ${ }^{7 \mathrm{~d}}$ In addition to these processes catalyzed by organometallic Lewis acids, other strategies have emerged with the development of interrupted Pummerer reaction/sigmatropic rearrangements, using charge-accelerated [3,3]-rearrangement. ${ }^{6,8,9}$ In this context, Maulide developed in 2018 a powerful methodology for the synthesis of functionalized 1,4-dicarbonyl compounds (Scheme 1c). ${ }^{9 \mathrm{e}}$ In the presence of triflimide, the ynamide derivatives are protonated to form a highly electrophilic keteniminium intermediate, which can undergo the addition of sulfoxides. The resulting key intermediate (III) could then perform a rearrangement to deliver after hydrolysis the corresponding $\gamma$-ketoamides. Furthermore, starting with enantiopure sulfoxides led to enantioenriched products, with a good chirality transfer. While ingenious, this methodology has some perfectible features, namely: (1) the use of ynamides as starting material, whose syntheses can sometimes be challenging or are commercially very expensive; (2) the use of a strong Brønsted acid, which must be handle carefully; (3) the use of mainly vinyl sulfoxides, without aryl groups $\left(\mathrm{R}^{3}, \mathrm{R}^{4} \neq\right.$ Ar). To overcome these limitations, we hypothesized that cationic gold(I) complexes could activate simple alkynes $\mathbf{1}$ via formation of $\pi$-complexes and allow the regioselective addition of the oxygen atom of the sulfoxide partner $2^{7 \mathrm{~h}}$ (Scheme 1d). Subsequently, the sulfonium intermediate (IV) should perform a [3,3]-sigmatropic rearrangement, to deliver a thionium ion (V). After hydrolysis, the corresponding 1,4-keto-aldehydes 3 should be isolated. 
Scheme 1. Sigmatropic rearrangement of sulfonium intermediates for the synthesis of carbonyl-containing compounds

a) Au-catalyzed rearrangement of alkynyl sulfoxides ${ }^{7 a, b}$

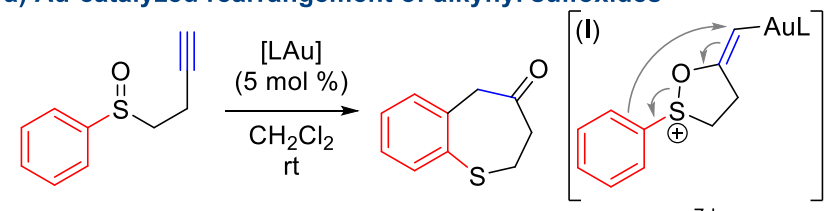

b) Intermolecular Au-catalyzed oxyarylation of alkynes ${ }^{7 \mathrm{~d}}$

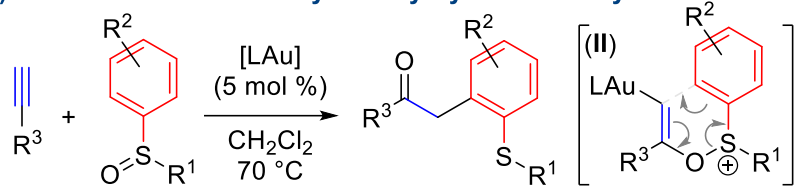

c) Acid-catalyzed rearrangement employing ynamides ${ }^{9 e}$

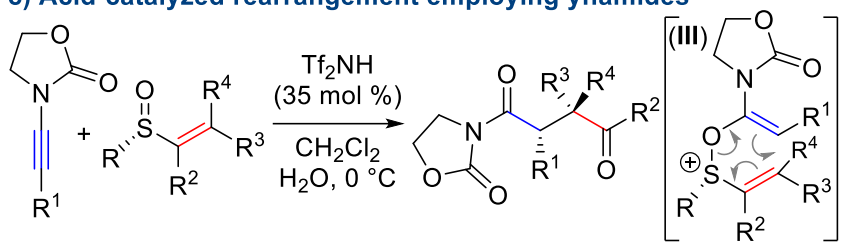

d) This work: Au-catalyzed rearrangement with alkynes and vinylsulfoxides

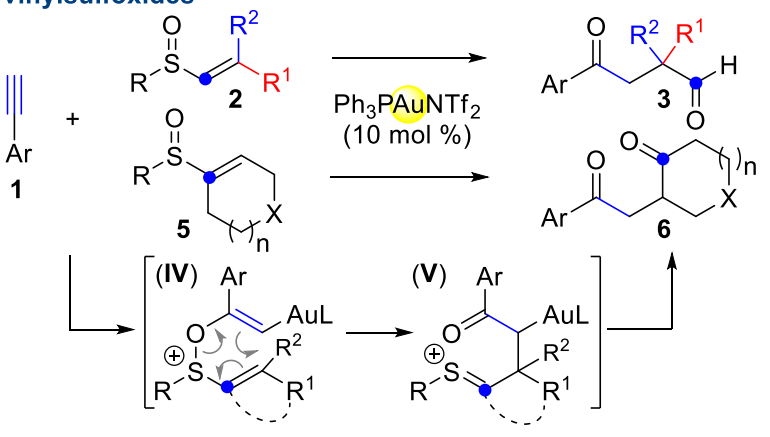

In this paper, we report our efforts in this direction and the extension of this methodology to the use of 1-cycloalkenyl sulfoxides $\mathbf{5}$ as starting materials, whose potential has so far been underexploited. The corresponding highly functionalized cycloalkyl ketones $\mathbf{6}$ have also been used as key building blocks for the rapid synthesis of five APIs.

Our study was initiated by reacting 1-ethynyl-4methoxybenzene 1a and sulfoxide $\mathbf{2 a}$, in the presence of $10 \mathrm{~mol}$ $\%$ of different gold(I) precatalysts, in dichloroethane at room temperature (Table 1). After activation with silver bis(trifluoromethanesulfonyl)imide, the corresponding cationic gold catalysts without ligand (entry 1) or coordinated with structurally diverse ligands such as an $N$-heterocyclic carbene (entry 2), triphenyl phosphite (entry 3 ) or phosphine ligands (entries 4-6) furnished the desired 2-(2-aryl-2oxoethyl)pentanal 3a in moderate yields. The formation of the bis(arylsulfane) by-product 3'a was also observed. A slight difference both in conversion and product selectivity $\mathbf{3 a} / \mathbf{3 a}$ ' was ascertained, depending on the catalyst used. We decided to continue our study with the commercially available $\mathrm{Ph}_{3} \mathrm{PAuCl}$ catalyst (entry 6). After verifying that it was necessary to form the cationic gold catalyst (entry 7), we added some water in the reaction mixture to facilitate the hydrolysis of the thionium ion and to favor the formation of $\mathbf{3 a}$ (entry 8). The expected effect was verified, since the yield of $\mathbf{3 a}$ increased from 48 to $72 \%$.
Table 1. Optimization of the Reaction Conditions

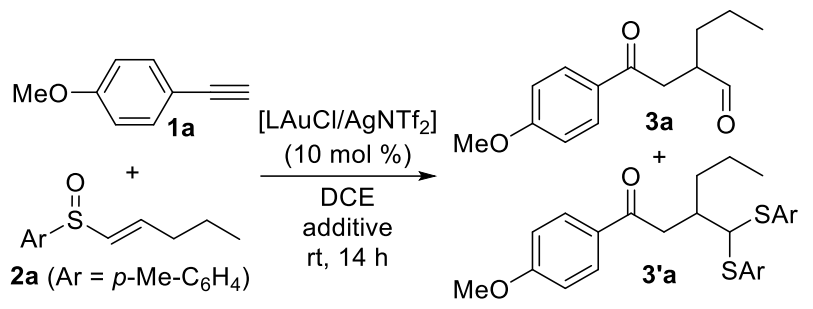

$\begin{array}{lllll}\text { entry } & {[\mathrm{Au}]} & \begin{array}{l}\text { Addi } \\ \text { tive }\end{array} & \begin{array}{l}\text { Conv. (\%) } \\ (\mathbf{3 a} / \mathbf{3} \text { 'a } \text { ratio })^{\mathrm{a}}\end{array} & \begin{array}{l}\text { 3a yield } \\ (\%)^{\mathrm{a}}\end{array} \\ 1 & \mathrm{AuCl} & - & 90(1 / 1.1) & 37 \\ 2 & \mathrm{IPrAuCl} & - & 90(1 / 1) & 43 \\ 3 & (\mathrm{PhO})_{3} \mathrm{PAuCl} & - & >98(1 / 1) & 50 \\ 4 & \mathrm{~L}_{1} \mathrm{AuCl} & - & 90(1.1 / 1) & 47 \\ 5 & \mathrm{~L}_{2} \mathrm{AuCl} & - & 83(1.8 / 1) & 53 \\ 6 & \mathrm{Ph}_{3} \mathrm{PAuCl} & - & >98(1 / 1) & 48 \\ 7^{\mathrm{b}} & \mathrm{Ph}_{3} \mathrm{PAuCl} & - & <5 & \mathrm{nd} \\ 8 & \mathrm{Ph}_{3} \mathrm{PAuCl} & \mathrm{H}_{2} \mathrm{O}^{\mathrm{c}} & >98(7 / 1) & 72 \\ 9^{\mathrm{d}} & - & \mathrm{H}_{2} \mathrm{O}^{\mathrm{c}} & 50(1 / 1) & 25 \\ 10 & \mathrm{Ph}_{3} \mathrm{PAuNTf} & \mathrm{H}_{2} \mathrm{O}^{\mathrm{c}} & >98(10 / 1) & 76(74)^{\mathrm{e}}\end{array}$

${ }^{a}$ Conversion, $3 \mathbf{3} / \mathbf{3}$ a' ratio and yield of $\mathbf{3 a}$ were determined by ${ }^{1} \mathrm{H}$ NMR analysis of the crude reaction mixture, with an internal standard. ${ }^{b}$ No silver salt was added. ${ }^{c} 3.0$ equiv of $\mathrm{H}_{2} \mathrm{O}$ was added. ${ }^{d}$ Only the silver salt $\mathrm{AgNTf}_{2}$ was used. elsolated yield. $\mathrm{L}_{1}=\mathrm{di}\left(1\right.$-adamantyl)-2-morpholinophenylphosphine; $\mathrm{L}_{2}=$ tris $(4$ methoxyphenyl)phosphine.

Silver salt alone does not efficiently catalyze the reaction (entry 9). It is noteworthy that the use of $\mathrm{HNTf}_{2}$ as catalyst gave the same disappointing results (38\% yield). Among all the different solvents and counteranion tested, $\mathrm{AgNTf}_{2}$ proved to be the best silver salt and DCE the best solvent (see Table S1). In fine, the optimal result was obtained with the use of $\mathrm{Ph}_{3} \mathrm{PAuNTf}_{2}$ preformed complex $(10 \mathrm{~mol} \%)$, in the presence of water at room temperature for $14 \mathrm{~h}$ (entry 10). The desired compound 3a was isolated in pure form in $74 \%$ yield. Under the optimized reaction conditions, we next examined the substrate scope, and the results are summarized in Scheme 2.

We started our study with the use of various substrates 2 a-e $\left(\mathrm{R}^{1}=\right.$ alkyl, $\mathrm{R}^{2}=\mathrm{H}$; Scheme $\left.2 \mathrm{a}\right)$. The products 3a,e were isolated in $44-74 \%$ yield. Product 3f, with a cyclohexyl-group was isolated in $64 \%$ yield. Interestingly, the methodology could be efficiently extended to the 2-aryl-vinylsulfoxide substrates 2g-i $\left(\mathrm{R}^{1}=\operatorname{aryl}, \mathrm{R}^{2}=\mathrm{H}\right)$. The 4-(4-methoxyphenyl)-4-oxo-2phenylbutanal $\mathbf{3 g}$ was synthesized in $77 \%$ yield on $1 \mathrm{mmol}$ scale. Regardless of the electron-donating para-methoxy- and electronegative $p$-fluoro-substituents, the corresponding products 3h-3i were obtained in 67-70\% yields. An heteroaryl substituent such as a thiophene group is also well tolerated (compound $\mathbf{3 j}, \mathbf{6 5 \%}$ yield). The second step was then to expend the substrate scope to various aryl alkynes $\mathbf{1 b}$-h (Scheme 2b). Seven different aryl-substituted alkynes reacted with vinyl sulfoxide 1a. Indeed, 1,2-dimethoxybenzene, 6-methoxynaphthalen and ferrocene-alkynes reacted smoothly to give the compounds 3k-m in up to $73 \%$ yield. Substrates possessing hydroxyl groups exhibited moderate yields in this transformation, because of the instability of both the alkyne substrates and the compounds $\mathbf{3 n}, \mathbf{p}$ under air atmosphere. 

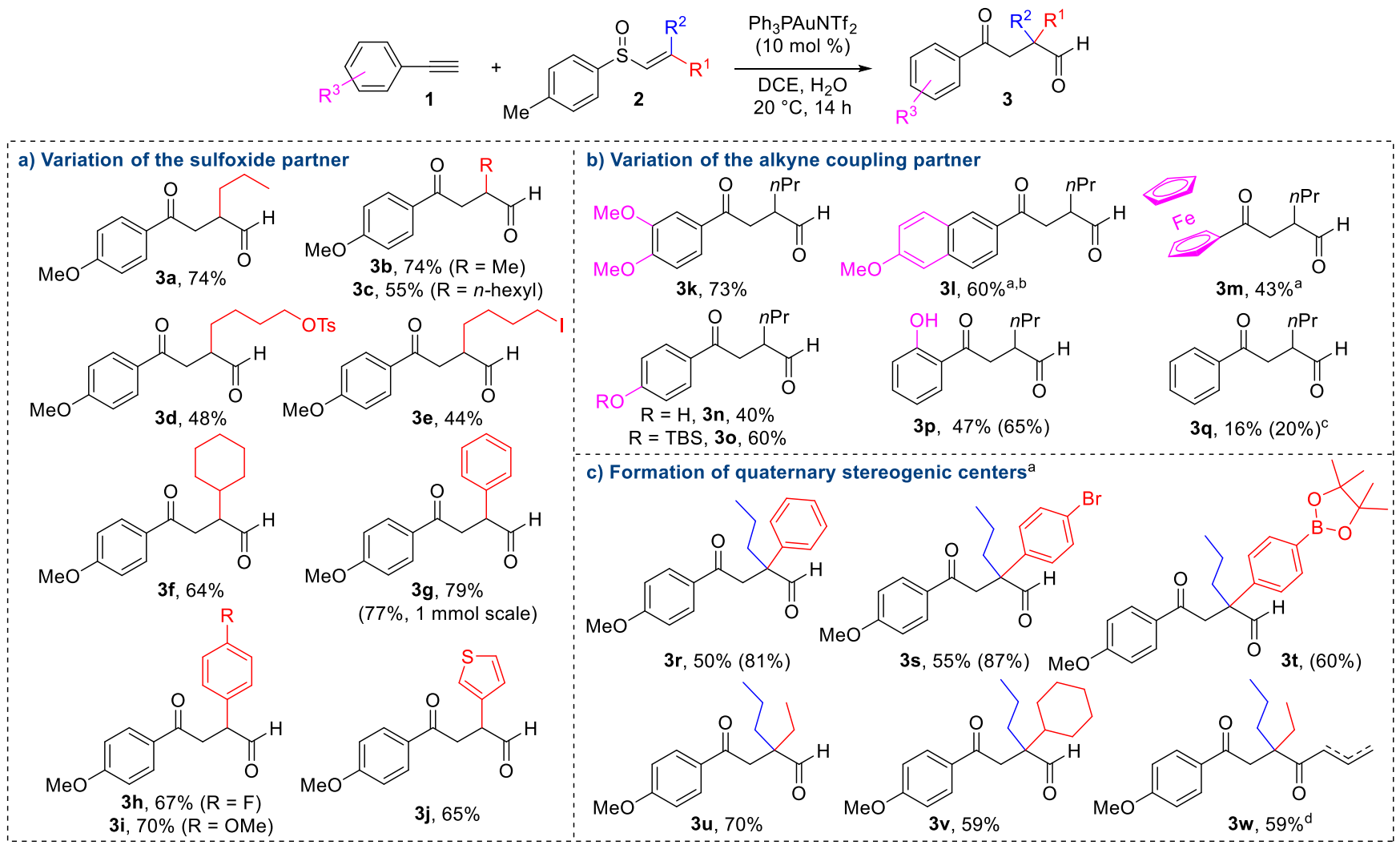

Isolated yield after purification by column chromatography on silica gel. NMR yields in parentheses. ${ }^{a}$ The presence of water was not required to improve yields. ${ }^{b}$ After $14 \mathrm{~h}$ reaction time, addition of chloreal, $\mathrm{AgNO}_{3}$ and $\mathrm{CdCO}_{3} .{ }^{c}(\mathrm{Johnphos}) \mathrm{AuCl} / \mathrm{AgNTf}_{2}$ catalyst, $60 \mathrm{~h}$ at rt. ${ }^{d}(Z)-1-((5-E$ thylocta-1,4-dien-4-yl)sulfinyl)-4methylbenzene was used as the sulfoxide substrate; mixture of two isomers of $3 \mathbf{w}$, in a $1 / 0.8$ ratio.

The use of TBS-protecting group increased the isolated yield to $60 \%$ (compound 3o). For the alkyne partner, electron-rich alkyne would appear to be necessary, since the use of ethynylbenzene provides the corresponding product $\mathbf{3 q}$ in only $20 \%$ yield. It is noteworthy that with this substrate, the use of $\mathrm{HNTf}_{2}$ did not furnish any conversion in the desired product. In a general way, with substrates having various substituents and/or electronic effects, the bis(arylthio)methyl derivatives 3' were rarely obtained in more than $10 \%$ yield and were easily separated from the target product with a simple purification step. Finally, six compounds possessing quaternary stereogenic centers were isolated in 50-70\% yields (compounds 3r-w, Scheme 2c). These last examples highlight the versatility of our methodology to access complex molecules in a single step. This 1,4-dicarbonyl derivative was next transformed into various useful disubstituted heterocycles such as pyrrole $\mathbf{4 a}$, furan $\mathbf{4 b}$ and thiophene $\mathbf{4 c}$ derivatives through Paal-Knorr reactions (Scheme S2). ${ }^{2}$

In the following of this work, we have considered 1cycloalkenyl sulfoxides $\mathbf{5 a - d ^ { 1 0 }}$ as potential substrates for this transformation (Scheme 3). These substrates have been scarcely used in [3,3]-sigmatropic rearrangements. Reaction of 5a-c with 1a, in the presence of $\mathrm{Ph}_{3} \mathrm{PAuNTf}_{2}(10 \mathrm{~mol} \%)$ led to compounds 6a-c in $67-85 \%$ yields, possessing respectively a five, six and seven-membered cyclo-alkyl-1-one backbone. These skeletons have already been synthesized, but using less direct synthetic pathways and/or more complex procedures. ${ }^{11}$ 3,6-Dihydro- $2 H$-thiopyran sulfoxide $\mathbf{5 d}$ was also engaged in the same transformation and product $\mathbf{6 d}$ was isolated in 55\% yield.
Finally, the substrate scope was extended to the use of the (4ethynylphenyl)(methyl)sulfane, to produce compounds $6 \mathbf{e - f}$ in $52 \%$ yield. We next envisioned the application of our methodology to the synthesis of API's (Scheme 4). The tetrahydrocyclopenta- $[b]$ pyrrole backbone is present in many bioactive molecules, as demonstrated by the known antiinflammatory activity ${ }^{12 \mathrm{a}-\mathrm{b}}$ of compound 7 or the inhibiting properties of compound $\mathbf{8}$ on the cyclooxygenase 2 (COX-2). ${ }^{12 \mathrm{~b}}$

Scheme 3. Au-catalyzed rearrangement of 1-cycloalkenyl sulfoxides 5a-d.

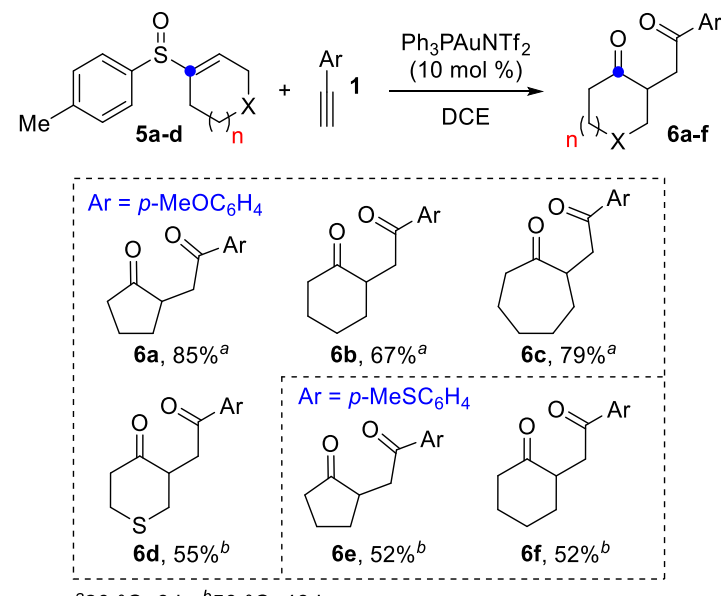

${ }^{a} 20^{\circ} \mathrm{C}, 6 \mathrm{~h},{ }^{b} 50^{\circ} \mathrm{C}, 48 \mathrm{~h}$ 
Scheme 4. Application of the methodology to the synthesis of API's

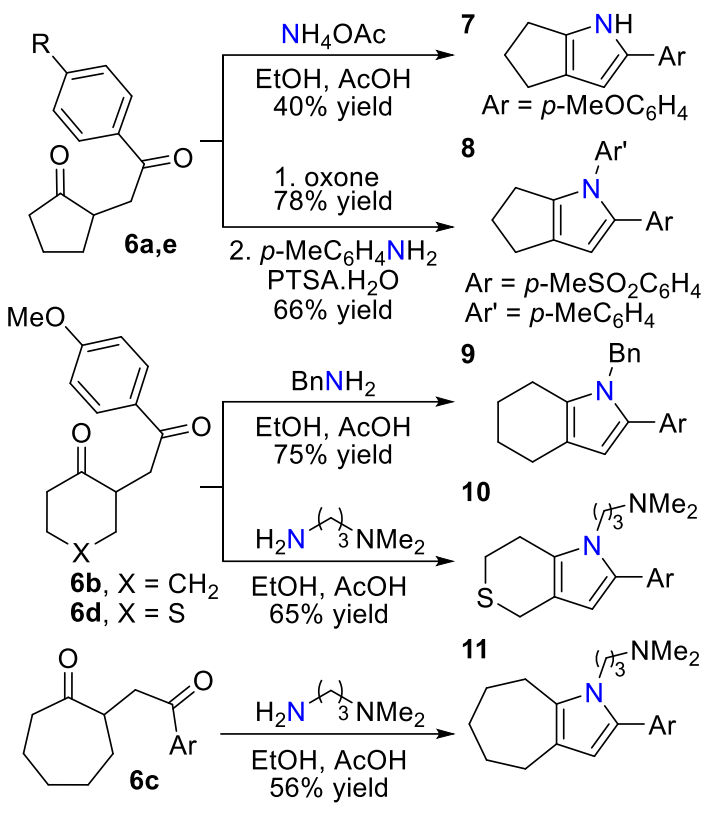

Using our methodology, we prepared easily 7 in $40 \%$ yield from diketone $\mathbf{6 a}(\mathrm{R}=\mathrm{OMe})$ and $\mathbf{8}$ from diketone $\mathbf{6 e}(\mathrm{R}=\mathrm{SMe}$, $66 \%$ yield), which was first oxidized to the corresponding sulfone. Starting from cyclohexanone $\mathbf{6 b}\left(\mathrm{X}=\mathrm{CH}_{2}\right)$, the PaalKnorr reaction with benzylamine gave access to a potent antihepatitis $C$ virus agent 9 in $75 \%$ yield. ${ }^{13}$ Finally, compounds $\mathbf{1 0}$ and 11 possess interesting properties as phosphodiesterase (PDE7) inhibitors, involved in inflammatory processes. ${ }^{13 \mathrm{~d}}$ They were synthesized in 56-65\% yield using dimethylpropane-1,3diamine and substrates $\mathbf{6 d}$ and $\mathbf{6 c}$.

Concerning the mechanism of this transformation, the cationic Au(I)-complex activates the alkyne $\mathbf{1}$ toward the addition of the vinylsulfoxide $\mathbf{2}$, to form the intermediate (IV) (Scheme 5a). Then, the sulfonium (IV) could perform a [3,3]sigmatropic rearrangement, to deliver the thionium ion $(\mathbf{V})$ (path a). After hydrolysis and protodemetallation step, the corresponding 1,4-dicarbonyls 3 are formed, in the presence of 4-methylbenzenethiol (TolSH). If the hydrolysis of ( $\mathbf{V})$ is not fast enough, the latter can do an addition on (V) to form the dithioacetal 3'. Different reaction conditions were screened to in situ convert the small amounts of $\mathbf{3}$ ' into $\mathbf{3}$. The addition after $14 \mathrm{~h}$ reaction time of chloreal, $\mathrm{AgNO}_{3}$ and $\mathrm{CdCO}_{3}$ allowed in some cases to increase the yield of $\mathbf{3}$ (see for instance compound 31 in Scheme 2). In a next step, we excluded a mechanism involving the in situ formation of $\alpha$-oxo gold carbenes (VI) ${ }^{14}$ and in situ generation of $p$-tolyl(vinyl)sulfane (VII) as potential nucleophile (path $b$, in red and Scheme S3). Finally, enantiopure sulfoxide $(R)-\mathbf{2} \mathbf{a}$ was engaged in the reaction with 1a under the optimized reaction conditions, leading to product 3a in $73 \%$ yield and $95 \%$ ee (Scheme 5 b). Starting from $(R)-2 c$, 3c was isolated with $90 \%$ ee. Interestingly, this asymmetric transformation can be extended to the synthesis of enantioenriched products possessing quaternary stereogenic centers (product 3r, 96\% ee). This excellent chirality transfer from sulfur to carbon attests that the reaction mechanism evolves most probably via a [3,3]-sigmatropic rearrangement. ${ }^{9 \mathrm{e}}$
Scheme 5. Mechanistic proposal and control experiments

a) Proposed mechanism

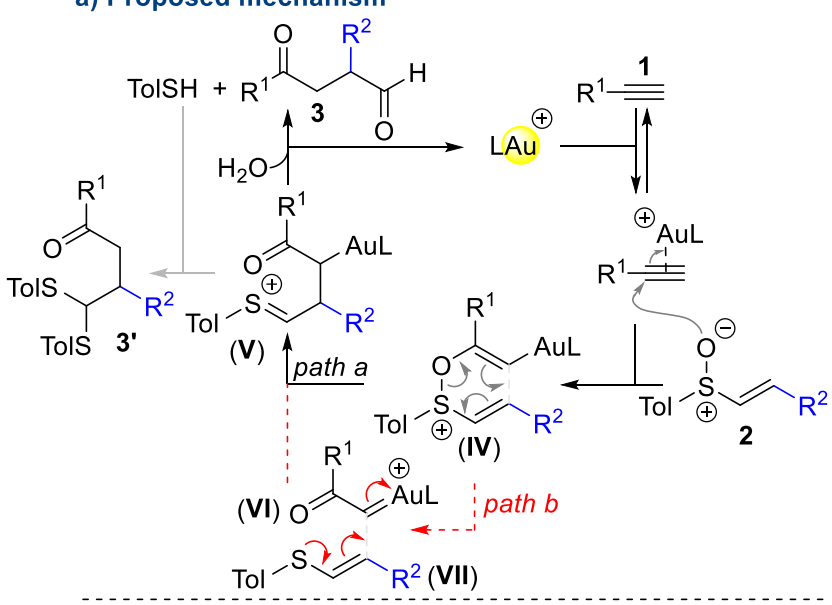

b) Asymmetric [3,3]-sigmatropic rearrangement
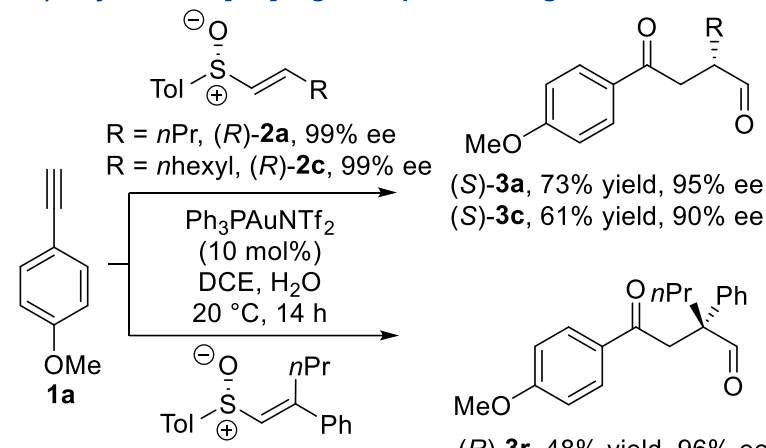

(S)-3a, $73 \%$ yield, $95 \%$ ee (S)-3c, $61 \%$ yield, $90 \%$ ee

$(R)-\mathbf{2 k}, 98 \%$ ee

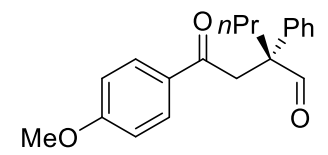

$(R)-3 \mathbf{r}, 48 \%$ yield, $96 \%$ ee

In summary, we have developed an efficient synthesis of 1,4dicarbonyl derivatives using simple alkyne substrates and vinylsulfoxides. Furthermore, this gold-catalyzed sulfonium $[3,3]$-sigmatropic rearrangement furnished an easy two-steps access to tetrahydrocycloalkyl[ $b]$ pyrroles, which is a pattern present in many bioactive molecules. Efforts are ongoing to expand the synthetic potential of this transformation, particularly in total synthesis of natural products.

\section{AUTHOR INFORMATION}

\section{Corresponding Author}

arnaud.voituriez@cnrs.fr

\section{ACKNOWLEDGMENT}

We thank the CSC (China Scholarship Council) for PhD grant to W. Z. and CNRS for financial support.

\section{REFERENCES}

(1) (a) Whittaker, M.; Floyd, C. D.; Brown, P.; Gearing, A. J. H. Design and Therapeutic Application of Matrix Metalloproteinase Inhibitors. Chem. Rev. 1999, 99, 2735-2776. (b) DeMartino, M. P.; Chen, K.; Baran, P. S. Intermolecular Enolate Heterocoupling: Scope, Mechanism, and Application. J. Am. Chem. Soc. 2008, 130, 1154611560. (c) Valot, G.; Regens, C. S.; O'Malley, D. P.; Godineau, E.; Takikawa, H.; Fürstner, A. Total Synthesis of Amphidinolide F. Angew. Chem. Int. Ed. 2013, 52, 9534-9538. (d) Gavai, A. V. et al. Discovery of Clinical Candidate BMS-906024: A Potent Pan-Notch Inhibitor for the Treatment of Leukemia and Solid Tumors. ACS Med. Chem. Lett. 2015, 6, 523-527. 
(2) General review on the Paal-Knorr reaction : Khaghaninejad, S.; Heravi, M. M. Adv. Heterocycl. Chem. 2014, 111, 95-146.

(3) (a) Ito, Y.; Konoike, T.; Saegusa, T. Synthesis of 1,4-diketones by the reaction of silyl enol ether with silver oxide. Regiospecific formation of silver(I) enolate intermediates. J. Am. Chem. Soc. 1975 97, 649-651. (b) Ito, Y.; Konoike, T.; Harada, T.; Saegusa, T. Synthesis of 1,4-diketones by oxidative coupling of ketone enolates with copper(II) chloride. J. Am. Chem. Soc. 1977, 99, 1487-1493. (c) Baran, P. S.; DeMartino, M. P. Intermolecular Oxidative Enolate Heterocoupling. Angew. Chem. Int. Ed. 2006, 45, 7083-7086. (d) Clift, M. D.; Taylor, C. N.; Thomson, R. J. Oxidative Carbon-Carbon Bond Formation via Silyl Bis-enol Ethers: Controlled Cross-Coupling for the Synthesis of Quaternary Centers. Org. Lett. 2007, 9, 4667-4669. (e) Ref 1b. (f) Amaya, T.; Maegawa, Y.; Masuda, T.; Osafune, Y.; Hirao, T. Selective Intermolecular Oxidative Cross-Coupling of Enolates. J. Am. Chem. Soc. 2015, 137, 10072-10075. For reviews, see : (g) Csákÿ, A. G.; Plumet, J. Stereoselective coupling of ketone and carboxylate enolates. Chem. Soc. Rev. 2001, 30, 313-320. (h) Guo, F.; Clift, M. D.; Thomson, R. J. Oxidative Coupling of Enolates, Enol Silanes, and Enamines: Methods and Natural Product Synthesis. Eur. J. Org. Chem. 2012, 4881-4896.

(4) (a) Enders, D.; Han, J.; Henseler, A. Asymmetric intermolecular Stetter reactions catalyzed by a novel triazolium derived $\mathrm{N}$ heterocyclic carbene. Chem. Commun. 2008, 3989-3991. (b) Liu, Q.; Perreault, S.; Rovis, T. Catalytic Asymmetric Intermolecular Stetter Reaction of Glyoxamides with Alkylidenemalonates. J. Am. Chem. Soc. 2008, 130, 14066-14067. (c) Jousseaume, T.; Wurz, N. E.; Glorius, F. Highly Enantioselective Synthesis of $\alpha$-Amino Acid Derivatives by an NHC-Catalyzed Intermolecular Stetter Reaction. Angew. Chem. Int. Ed. 2011, 50, 1410-1414. (d) Wilde, M. M. D.; Gravel, M. Bis(amino)cyclopropenylidenes as Organocatalysts for Acyl Anion and Extended Umpolung Reactions. Angew. Chem. Int. Ed. 2013, 52, 12651-12654. (e) Chen, X.-Y.; Enders, D., Radical Umpolung: Efficient Options for the Synthesis of 1,4-Dicarbonyl Compounds. Angew. Chem. Int. Ed. 2019, 58, 6488-6490. (f) Kise, N.; Tokioka, K.; Aoyama, Y.; Matsumura, Y. Enantioselective Synthesis of 2,3-Disubstituted Succinic Acids by Oxidative Homocoupling of Optically Active 3-Acyl-2-oxazolidones. J. Org. Chem. 1995, 60, 1100-1101. (g) Yasuda, M.; Tsuji, S.; Shigeyoshi, Y.; Baba, A. CrossCoupling Reaction of $\alpha$-Chloroketones and Organotin Enolates Catalyzed by Zinc Halides for Synthesis of $\gamma$-Diketones. J. Am. Chem. Soc. 2002, 124, 7440-7447. (h) Luo, J.; Jiang, Q.; Chen, H.; Tang, Q. Catalyst-free formation of 1,4-diketones by addition of silyl enolates to oxyallyl zwitterions in situ generated from $\alpha$-haloketones. RSC Advances 2015, 5, 67901-67908. (i) Kaiser, D.; Teskey, C. J.; Adler, P.; Maulide, N. Chemoselective Intermolecular Cross-Enolate-Type Coupling of Amides. J. Am. Chem. Soc. 2017, 139, 16040-16043. (j) Jang, H.-Y.; Hong, J.-B.; MacMillan, D. W. C. Enantioselective Organocatalytic Singly Occupied Molecular Orbital Activation: The Enantioselective $\alpha$-Enolation of Aldehydes. J. Am. Chem. Soc. 2007, 129, 7004-7005. (k) Yasu, Y.; Koike, T.; Akita, M. Sunlight-driven synthesis of $\gamma$-diketones via oxidative coupling of enamines with silyl enol ethers catalyzed by $\left[\mathrm{Ru}(\mathrm{bpy})_{3}\right]^{2+}$. Chem. Commun. 2012, 48, 53555357. (1) Zhang, F.; Du, P.; Chen, J.; Wang, H.; Luo, Q.; Wan, X. CoCatalyzed Synthesis of 1,4-Dicarbonyl Compounds Using TBHP Oxidant. Org. Lett. 2014, 16, 1932-1935. (m) Morack, T.; MückLichtenfeld, C.; Gilmour, R. Bioinspired Radical Stetter Reaction: Radical Umpolung Enabled by Ion-Pair Photocatalysis. Angew. Chem. Int. Ed. 2019, 58, 1208-1212. (n) Goti, G.; Bieszczad, B.; VegaPeñaloza, A.; Melchiorre, P. Stereocontrolled Synthesis of 1,4 Dicarbonyl Compounds by Photochemical Organocatalytic Acyl Radical Addition to Enals. Angew. Chem. Int. Ed. 2019, 58, 1213-1217. (o) Kuang, Y.; Wang, K.; Shi, X.; Huang, X.; Meggers, E.; Wu, J. Asymmetric Synthesis of 1,4-Dicarbonyl Compounds from Aldehydes by Hydrogen Atom Transfer Photocatalysis and Chiral Lewis Acid Catalysis. Angew. Chem. Int. Ed. 2019, 58, 16859-16863.

(5) Representative publications : (a) Moriarty, R. M.; Prakash, O.; Duncan, M. P. Carbon-carbon bond formation using hypervalent iodine under Lewis acid conditions: 1,4-diarylbutane-1,4-diones. $J$. Chem. Soc., Chem. Commun. 1985, 420-420. (b) Aoki, S.; Nakamura, E. Synthesis of 1,4-dicarbonyl compounds and 4-keto pimelates by palladium-catalyzed carbonylation of siloxycyclopropanes. Tetrahedron 1991, 47, 3935-3946. (c) Echavarren, A. M.; Pérez, M.; Castano, A. M.; Cuerva, J. M. Palladium-Catalyzed Reductive Coupling of Acid Chlorides with $\beta$-Stannyl Enones: Synthesis of 1,4Diketones and Mechanistic Aspects. J. Org. Chem. 1994, 59, 41794185. (d) Yin, H.; Nielsen, D. U.; Johansen, M. K.; Lindhardt, A. T.; Skrydstrup, T. Development of a Palladium-Catalyzed Carbonylative Coupling Strategy to 1,4-Diketones. ACS Catalysis 2016, 6, 29822987. (e) Rong, J.; Li, H.; Fu, R.; Sun, W.; Loh, T.-P.; Jiang, Y. Cleavage and Reassembly $\mathrm{C} \equiv \mathrm{C}$ Bonds of Ynones to Access Highly Functionalized Ketones. ACS Catalysis 2020, 10, 3664-3669.

(6) (a) Smith, L. H. S.; Coote, S. C.; Sneddon, H. F.; Procter, D. J. Beyond the Pummerer Reaction: Recent Developments in Thionium Ion Chemistry. Angew. Chem. Int. Ed. 2010, 49, 5832-5844. (b) Huang, X.; Klimczyk, S.; Maulide, N., Charge-Accelerated Sulfonium [3,3]Sigmatropic Rearrangements. Synthesis 2012, 44, 175-183. (c) Pulis, A. P.; Procter, D. J. C-H Coupling Reactions Directed by Sulfoxides: Teaching an Old Functional Group New Tricks. Angew. Chem. Int. Ed. 2016, 55, 9842-9860. (d) Yorimitsu, H. Cascades of Interrupted Pummerer Reaction-Sigmatropic Rearrangement. Chem. Rec. 2017, 17, 1156-1167. (e) Yanagi, T.; Nogi, K.; Yorimitsu, H. Recent development of ortho-C-H functionalization of aryl sulfoxides through [3,3] sigmatropic rearrangement. Tetrahedron Lett. 2018, 59, 29512959. (f) Kaiser, D.; Klose, I.; Oost, R.; Neuhaus, J.; Maulide, N. BondForming and -Breaking Reactions at Sulfur(IV): Sulfoxides, Sulfonium Salts, Sulfur Ylides, and Sulfinate Salts. Chem. Rev. 2019, 119, 87018780 .

(7) (a) Shapiro, N. D.; Toste, F. D. Rearrangement of Alkynyl Sulfoxides Catalyzed by Gold(I) Complexes. J. Am. Chem. Soc. 2007, 129, 4160-4161. (b) Li, G.; Zhang, L. Gold-Catalyzed Intramolecular Redox Reaction of Sulfinyl Alkynes: Efficient Generation of $\alpha$-Oxo Gold Carbenoids and Application in Insertion into R-CO Bonds. Angew. Chem. Int. Ed. 2007, 46, 5156-5159. (c) Lu, B.; Li, Y.; Wang, Y.; Aue, D. H.; Luo, Y.; Zhang, L. [3,3]-Sigmatropic Rearrangement versus Carbene Formation in Gold-Catalyzed Transformations of Alkynyl Aryl Sulfoxides: Mechanistic Studies and Expanded Reaction Scope. J. Am. Chem. Soc. 2013, 135, 8512-8524. (d) Cuenca, A. B.; Montserrat, S.; Hossain, K. M.; Mancha, G.; Lledós, A.; Medio-Simón, M.; Ujaque, G.; Asensio, G. Gold(I)-Catalyzed Intermolecular Oxyarylation of Alkynes: Unexpected Regiochemistry in the Alkylation of Arenes. Org. Lett. 2009, 11, 4906-4909. (e) Li, C.-W.; Pati, K.; Lin, G.-Y.; Sohel, S. M. A.; Hung, H.-H.; Liu, R.-S. GoldCatalyzed Oxidative Ring Expansions and Ring Cleavages of Alkynylcyclopropanes by Intermolecular Reactions Oxidized by Diphenylsulfoxide. Angew. Chem. Int. Ed. 2010, 49, 9891-9894. (f) Barrett, M. J.; Davies, P. W.; Grainger, R. S. Regioselective functionalisation of dibenzothiophenes through gold-catalysed intermolecular alkyne oxyarylation. Org. Biomol. Chem. 2015, 13, 8676-8686. (g) Murakami, K.; Imoto, J.; Matsubara, H.; Yoshida, S.; Yorimitsu, H.; Oshima, K., Copper-Catalyzed Extended Pummerer Reactions of Ketene Dithioacetal Monoxides with Alkynyl Sulfides and Ynamides with an Accompanying Oxygen Rearrangement. Chem. Eur. J. 2013, 19, 5625-5630. For general reviews on gold-catalysis, see : (h) Dorel, R.; Echavarren, A. M. Gold(I)-Catalyzed Activation of Alkynes for the Construction of Molecular Complexity. Chem. Rev. 2015, 115, 9028-9072. (i) Wei, Y.; Shi, M. Divergent Synthesis of Carbo- and Heterocycles via Gold-Catalyzed Reactions. ACS Catalysis 2016, 6, 2515-2524.

(8) Representative examples: (a) Yoshida, S.; Yorimitsu, H.; Oshima, K., 2-(2,2,2-Trifluoroethylidene)-1,3-dithiane Monoxide as a Trifluoromethylketene Equivalent. Org. Lett. 2009, 11 2185-2188. (b) Kobatake, T.; Yoshida, S.; Yorimitsu, H.; Oshima, K., Reaction of 2(2,2,2-Trifluoroethylidene)-1,3-dithiane 1-Oxide with Ketones under Pummerer Conditions and Its Application to the Synthesis of 3Trifluoromethyl-Substituted Five-Membered Heteroarenes. Angew. Chem. Int. Ed. 2010, 49, 2340-2343. (c) Huang, X.; Maulide, N., Sulfoxide-Mediated $\alpha$-Arylation of Carbonyl Compounds. J. Am. Chem. Soc. 2011, 133, 8510-8513. (d) Eberhart, A. J.; Imbriglio, J. E.; Procter, D. J., Nucleophilic Ortho Allylation of Aryl and Heteroaryl Sulfoxides. Org. Lett. 2011, 13, 5882-5885. (e) Yanagi, T.; Otsuka, S.; Kasuga, Y.; Fujimoto, K.; Murakami, K.; Nogi, K.; Yorimitsu, H.; 
Osuka, A. Metal-Free Approach to Biaryls from Phenols and Aryl Sulfoxides by Temporarily Sulfur-Tethered Regioselective C-H/C-H Coupling. J. Am. Chem. Soc. 2016, 138, 14582-14585. (f) FernándezSalas, J. A.; Eberhart, A. J.; Procter, D. J. Metal-Free CH-CH-Type Cross-Coupling of Arenes and Alkynes Directed by a Multifunctional Sulfoxide Group. J. Am. Chem. Soc. 2016, 138, 790-793. (g) Shrives, H. J.; Fernández-Salas, J. A.; Hedtke, C.; Pulis, A. P.; Procter, D. J. Regioselective synthesis of $\mathrm{C} 3$ alkylated and arylated benzothiophenes. Nat. Commun. 2017, 8, 14801. (h) He, Z.; Shrives, H. J.; FernándezSalas, J. A.; Abengózar, A.; Neufeld, J.; Yang, K.; Pulis, A. P.; Procter, D. J. Synthesis of C2 Substituted Benzothiophenes via an Interrupted Pummerer/[3,3]-Sigmatropic/1,2-Migration Cascade of Benzothiophene S-Oxides. Angew. Chem. Int. Ed. 2018, 57, 57595764.

(9) (a) Peng, B.; Huang, X.; Xie, L.-G.; Maulide, N. A Brønsted Acid Catalyzed Redox Arylation. Angew. Chem. Int. Ed. 2014, 53, 8718-8721. (b) Kaiser, D.; Veiros, L. F.; Maulide, N. Brønsted AcidMediated Hydrative Arylation of Unactivated Alkynes. Chem. Eur. J. 2016, 22, 4727-4732. (c) Kaiser, D.; Veiros, L. F.; Maulide, N. RedoxNeutral Arylations of Vinyl Cation Intermediates. Adv. Synth. Catal. 2017, 359, 64-77. (d) Kaldre, D.; Maryasin, B.; Kaiser, D.; Gajsek, O.; González, L.; Maulide, N. An Asymmetric Redox Arylation: Chirality Transfer from Sulfur to Carbon through a Sulfonium [3,3]-Sigmatropic Rearrangement. Angew. Chem. Int. Ed. 2017, 56, 2212-2215. (e) Kaldre, D.; Klose, I.; Maulide, N. Stereodivergent synthesis of 1,4dicarbonyls by traceless charge-accelerated sulfonium rearrangement. Science 2018, 361, 664-667. For related studies, see: (f) Hu, L.; Gui, Q.; Chen, X.; Tan, Z.; Zhu, G. HOTf-Catalyzed, Solvent-Free Oxyarylation of Ynol Ethers and Thioethers. J. Org. Chem. 2016, 81, 4861-4868.

(10) (a) Marino, J. P.; Perez, A. D. Enantiospecific lactonizations of chiral 1-(arylsulfinyl)cyclohexenes with chloro ketenes. J. Am. Chem. Soc. 1984, 106, 7643-7644. (b) Kunio, H.; Nobuhiko, M. A Novel and Useful Synthetic Way to Chiral $\alpha$-Sulfinyl Cyclic Ketones by the AcidCatalyzed Reaction of Enol Silyl Ethers of Cyclic Ketones with Chiral Sulfinates. Chem. Lett. 1986, 15, 65-68. (c) Iwata, C.; Maezaki, N.; Kurumada, T.; Fukuyama, H.; Sugiyama, K.; Imanishi, T. New carbon-carbon bond formation by the Pummerer-type reaction of vinylic sulphoxides with allylmagnesium bromide. J. Chem. Soc., Chem. Commun. 1991, 1408-1409. (d) Maezaki, N.; Izumi, M.; Yuyama, S.; Iwata, C.; Tanaka, T. Intramolecular alkylation of an $\alpha$ sulfinyl vinylic carbanion without loss of optical purity: a novel access to chiral cyclic vinylic sulfoxides. Chem. Commun. 1999, 1825-1826. (e) Maezaki, N.; Izumi, M.; Yuyama, S.; Sawamoto, H.; Iwata, C.; Tanaka, T. Studies on Intramolecular Alkylation of an $\alpha$-Sulfinyl Vinylic Carbanion: a Novel Route to Chiral 1-Cycloalkenyl Sulfoxides. Tetrahedron 2000, 56, 7927-7945. (f) Díaz Buezo, N.; de la Rosa, J. C.; Priego, J.; Alonso, I.; Carretero, J. C. Sulfoxides as Stereochemical Controllers in Intermolecular Heck Reactions. Chem. Eur. J. 2001, 7, 3890-3900.

(11) For representative examples, see: (a) Li, Y.; Shang, J.-Q.; Wang, X.-X.; Xia, W.-J.; Yang, T.; Xin, Y.; Li, Y.-M. CopperCatalyzed Decarboxylative Oxyalkylation of Alkynyl Carboxylic Acids: Synthesis of $\gamma$-Diketones and $\gamma$-Ketonitriles. Org. Lett. 2019, 21, 2227-2230. (b) Arceo, E.; Bahamonde, A.; Bergonzini, G.; Melchiorre, P. Enantioselective direct $\alpha$-alkylation of cyclic ketones by means of photo-organocatalysis. Chem. Sci. 2014, 5, 2438-2442. (c) Sun, H.; Yang, C.; Gao, F.; Li, Z.; Xia, W., Oxidative C-C Bond Cleavage of Aldehydes via Visible-Light Photoredox Catalysis. Org. Lett. 2013, 15, 624-627. (d) Yasu, Y.; Koike, T.; Akita, M. Sunlight-driven synthesis of $\gamma$-diketones via oxidative coupling of enamines with silyl enol ethers catalyzed by $\left[\mathrm{Ru}(\mathrm{bpy})_{3}\right]^{2+}$. Chem. Commun. 2012, 48, 5355-5357. (e) Xie, J.; Huang, Z.-Z. The cascade carbo-carbonylation of unactivated alkenes catalyzed by an organocatalyst and a transition metal catalyst: a facile approach to $\gamma$-diketones and $\gamma$-carbonyl aldehydes from arylalkenes under air. Chem. Commun. 2010, 46, 1947-1949. (f) Fujii, T.; Hirao, T.; Ohshiro, Y. Oxovanadium-induced oxidative desilylation for the selective synthesis of 1,4-diketones. Tetrahedron Lett. 1992, 33, $5823-5826$

(12) (a) Xu, X.-T.; Mou, X.-Q.; Xi, Q.-M.; Liu, W.-T.; Liu, W.-F.; Sheng, Z.-J.; Zheng, X.; Zhang, K.; Du, Z.-Y.; Zhao, S.-Q.; Wang, S.-
H. Anti-inflammatory activity effect of 2-substituted-1,4,5,6tetrahydrocyclopenta[b]pyrrole on TPA-induced skin inflammation in mice. Bio. Med. Chem. Lett. 2016, 26, 5334-5339. (b) Zhong, B. H.; Li, M. Y. China Pat. 2007 CN 1995163A. (c) Mou, X.-Q.; Xu, Z.-L.; Wang, S.-H.; Zhu, D.-Y.; Wang, J.; Bao, W.; Zhou, S.-J.; Yang, C.; Zhang, D. An $\mathrm{Au}(\mathrm{I})$-catalyzed rearrangement/cyclization cascade toward the synthesis of 2-substituted-1,4,5,6tetrahydrocyclopenta[b]pyrrole. Chem. Commun. 2015, 51, 1206412067. (d) François, B.; Eberlin, L.; Berrée, F.; Whiting, A.; Carboni, B. Access to Fused Pyrroles from Cyclic 1,3-Dienyl Boronic Esters and Arylnitroso Compounds. J. Org. Chem. 2020, 85, 5173-5182.

(13) (a) Andreev, I. A.; Manvar, D.; Barreca, M. L.; Belov, D. S.; Basu, A.; Sweeney, N. L.; Ratmanova, N. K.; Lukyanenko, E. R.; Manfroni, G.; Cecchetti, V.; Frick, D. N.; Altieri, A.; Kaushik-Basu, N.; Kurkin, A. V. Discovery of the 2-phenyl-4,5,6,7-Tetrahydro-1Hindole as a novel anti-hepatitis $\mathrm{C}$ virus targeting scaffold. Eur. J. Med. Chem. 2015, 96, 250-258. (b) Andreev, I. A.; Belov, D. S.; Kurkin, A. V.; Yurovskaya, M. A. Synthesis of 4,5,6,7-Tetrahydro-1H-indole Derivatives Through Successive Sonogashira Coupling/Pd-Mediated 5-endo-dig Cyclization. Eur. J. Org. Chem. 2013, 649-652. (c) Anderson, V. B.; Agnew, M. N.; Allen, R. C.; Wilker, J. C.; Lassman, H. B.; Novick, W. J. Carboxyarylindoles as nonsteroidal antiinflammatory agents. J. Med. Chem. 1976, 19, 318-325. (d) Jpn. Kokai Tokkyo Koho 2006, JP 2006290791.

(14) (a) Li, J.; Ji, K.; Zheng, R.; Nelson, J.; Zhang, L. Expanding the horizon of intermolecular trapping of in situ generated $\alpha$-oxo gold carbenes: efficient oxidative union of allylic sulfides and terminal alkynes via $\mathrm{C}-\mathrm{C}$ bond formation. Chem. Commun. 2014, 50, 41304133. (b) Santos, M. D.; Davies, P. W. A gold-catalysed fully intermolecular oxidation and sulfur-ylide formation sequence on ynamides. Chem. Commun. 2014, 50, 6001-6004. (c) Zhang, L. A NonDiazo Approach to alpha-Oxo Gold Carbenes via Gold-Catalyzed Alkyne Oxidation. Acc. Chem. Res. 2014, 47, 877-888. (d) Stow, C. P.; Widenhoefer, R. A. Synthesis, Structure, and Reactivity of Gold(I) $\alpha$ Oxo Carbenoid Complexes. Organometallics 2020, 39, 1249-1257. 